\title{
Targeting of Somatostatin Receptors Using Fluorescent Nanoparticles
}

\section{Ahmed A.H. Abdellatif $12^{*}$}

${ }^{1}$ Department of Pharmaceutics and Industrial Pharmacy, Faculty of Pharmacy, Al-Azhar University, Assiut, Egypt.

${ }^{2}$ Department of Pharmaceutics, Faculty of Pharmacy, Qassim University, Buraydah, Kingdom of Saudi Arabia.

\begin{abstract}
The main goal of this work was to recognize how nanoparticles target certain sites in the body with certain targeting peptides to specific receptor by active targeting. The study focused on the methods of preparation and the characterization of quantum dots (QDs) carrying a PEG-amine which were conjugated to somatostatin to give QDsSST. This was followed by successful cellular uptake experiments. The results showed a successful characterization for QDs-conjugated SST. Cellular uptake showed highly specific interactions with cells using flow cytometry and inductively coupled plasma optical emission spectroscopy. The QDs-SST can be displaced from their receptor, which relates to the specificity of the interaction with somatostatin receptor. In conclusion, SST can deliver the nanoparticles to the targeted sites with high drug delivery efficacy in vitro due to decoration with SST.
\end{abstract}

Keywords: Quantum dots; Somatostatin; Somatostatin receptors

\section{Introduction}

The targeted delivery of NPs to a specific site in the body has great potential to improve drug therapy. Through improved targeting, drawbacks in contemporary drug therapy could be overcome [1,2]. In successful targeting, the therapeutically active materials would be distributed to a specific region in the body and thus side effects and toxic reactions could be decreased significantly [3]. To improve the bio-distribution of the target nanoparticles, nanoparticles loaded with active drugs which are carried to receptor cells by selectively using water-soluble QDs. The proper delivery of these nanoparticles would greatly benefit new therapeutic strategies, such as gene therapy of diseased cells, where it is essential to direct treatment to specific site in the body [4-6].

SSTRs are members of the G protein-coupled receptors (GPCRs) superfamily $[7,8]$. SSTRs are one class of receptors that could be targeted using NPs. These receptors are found either exposed on the surface of the cell or within the cell [9-11]. These cells are target cells for that ligand while cells which do not have such a receptor cannot be influenced directly by that ligand [12]. There are five different SSTRs subtypes (SSTR1-5) since they are expressed at various sites in the body and distributed in different organs [13-15]. SSTRs are also expressed on blood cells [16-22]. They bind with the natural SST and its analogues with low nanomolar affinity $[8,23,24]$.

Quantum dots (QDs) are little semiconductor particles, just a few nanometers in estimate, so little that their optical and electronic properties vary from those of bigger particles. They are a focal topic in nanotechnology. Numerous kinds of a quantum dot will radiate light of particular frequencies if power or light is connected to them, and these frequencies can be accurately tuned by changing the dots' size, [25] shape and material, offering ascend to numerous applications. In the dialect of materials science, nanoscale semiconductor materials firmly keep either electrons or electron gaps. QDs are additionally here and there alluded to as counterfeit particles, a term that stresses that a quantum speck is a solitary question with bound, discrete electronic states, similar to the case with normally happening iotas or molecules. [26]. QDs display properties that are middle between those of mass semiconductors and those of discrete particles. Their optoelectronic properties change as a component of both size and shape [27]. Larger QDs (sweep of 5- $6 \mathrm{~nm}$, for instance) radiate longer wavelengths bringing about emanation hues, for example, orange or red. Littler QDs (range of 2-3 nm, for instance) produce shorter wavelengths bringing about hues like blue and green, in spite of the fact that the particular hues and sizes shift contingent upon the correct organization of the QD. As a result of their very tunable properties, QDs are of wide intrigue. Potential applications incorporate transistors, sunlight based cells, LEDs, diode lasers and second-consonant age, quantum figuring, and restorative imaging [28]. Additionally, their little size takes into consideration QDs to be suspended in an answer which prompts conceivable uses in inkjet printing and turn coating [29]. These handling strategies result in more affordable and less tedious techniques for semiconductor creation.

Nowadays, different sorts of organic dyes are utilized. In any case, as innovation progresses, more noteworthy adaptability in these dyes is sought [30]. To this field, quantum specks have immediately filled in the part, being observed to be better than customary natural dyes on a few checks, a standout amongst the most quickly evident being shine (inferable from the high elimination coefficient joined with a similar quantum respect fluorescent dyes [31] and in addition their steadiness (permitting significantly less photo bleaching).It has been assessed that quantum spots are 20 times brighter and 100 times more steady than conventional fluorescent reporters [30]. Moreover, the unpredictable flickering of QDs is a minor drawback. Also, there have been groups which have created QDs which are essentially non blinking and demonstrated their utility in single molecule tracking experiments [32].

The utilization of QDs for exceptionally delicate cell imaging has seen major advances [33]. The enhanced photo stability of QDs, for instance, permits the obtaining of numerous back to back central plane pictures that can be remade into a high-determination three-dimensional image [34]. Another application that exploits the uncommon photo stability of quantum dot tests is the constant following of atoms and cells over expanded times of time [35]. Antibodies, streptavidin [36], peptides [37], DNA [38], nucleic corrosive aptamers [39], or little particle ligands can be utilized to target QDs to particular proteins on cells.

*Corresponding author: Ahmed $\mathrm{AH}$ Abdellatif, Department of Pharmaceutics, Faculty of Pharmacy, Qassim University, Buraydah, Kingdom of Saudi Arabia, E-mail: ahmed.abdellatif@hotmail.de

Received: June 04, 2018; Accepted: June 19, 2018; Published: June 25, 2018

Citation: Abdellatif AAH (2018) Targeting of Somatostatin Receptors Using Fluorescent Nanoparticles. J Nanomed Nanotechnol 9: 506. doi: 10.4172/21577439.1000506

Copyright: $\odot 2018$ Abdellatif AAH. This is an open-access article distributed under the terms of the Creative Commons Attribution License, which permits unrestricted use, distribution, and reproduction in any medium, provided the original author and source are credited. 
Analysts could watch QDs in lymph nodes of mice for more than 4 months [40].

SST has numerous functions in mammals; it can be as regulators for secretion of growth hormones [41]. Furthermore, it is widely circulated throughout the central nervous system and peripheral tissues there playing many roles in the central nervous system [42,43]. Moreover, SST prevents the regulation of many endogenous cell functions, comprising the modulation of neurotransmission, motility, cell proliferation and cell secretion $[44,45]$. The limited stability of SST and the existence of many functional groups make the interaction with other compounds is difficult [46]. To conjugate SST to QDs, SST was thiolated then conjugated to sulfo-SMCC-QDs as a step that can easy the activation of QDs with SST. The conjugation started with the thiolation of SST using Traut's reagent. On the other hand, the QDs that carry PEG-amine chains were activated by sulfo-SMCC dissolved in an activation buffer. The sulfo-SMCC activated QDs were conjugated to the thiolated-SST to form SST-QDs. The cellular uptake of QDs-SST was studied using MCF7 cells. MCF7 cells were incubated with QDs-SST for 1 hour. The number of QDs per cell was determined by ICP-OES.

\section{Materials and Methods}

\section{Materials}

Somatostatin acetate (SST) was kindly supplied from CuraMED Pharma GmbH (Karlsruhe, Germany). Hydrogen tetrachloroaurate tri-hydrate, Traut's reagent (2-iminothiolane hydrochloride), Ellman's reagent (5,5'-dithiobis-(2-nitrobenzoic acid)). QDs carrying PEGamine were purchased from Invitrogen (Darmstadt, Germany). The ultrafiltration units had a $100-\mathrm{kDa}$ cut-off membrane was purchased from Amicon Ultra-4 Millipore (Billerica, MA). Dulbecco`s phosphate buffered saline ( $\mathrm{pH}$ 7.4), Dulbecco's Modified Eagle Medium, and Leibovitz's L-15 were purchased from Invitrogen, (paisley, UK).

The purified water used for all experiment was obtained using a Milli-Q water purification system from Millipore (Schwalbach, Garmany). All glassware were thoroughly washed with freshly prepared aqua regia $\left(\mathrm{HCl}: \mathrm{HNO}_{3}, 3: 1\right)$, extensively rinsed with Millipore water several times and oven-dried at $50^{\circ} \mathrm{C}$ for $2-3$ hours before use.

\section{Conjugation of somatostatin to quantum dot nanoparticles}

The conjugation of SST to QDs started with the thiolation of SST using Traut's reagent. On the other hand, the QDs were subsequently activated by a 500 -fold molar excess of sulfo-SMCC dissolved in an activation buffer to yield a final volume of $250 \mu \mathrm{L}$. The activated QDs sulfo-SMCC was conjugated to the thiolated-SST to form SST-QDs (Figure 1). The obtained bio-conjugate was purified by centrifugation using an ultrafiltration tube (Amicon Ultra-4, 100K MWCO; GE Healthcare) [47].

\section{Characterization of somatostatin coated quantum dots}

The zeta potential was determined using a Malvern Zetasizer Nano (Malvern Instruments GmbH, Herrenberg, Germany). Fluorescence emission spectra of QDs and QDs-SST were recorded in order to determine the shift obtained after conjugation of SST to QDs. The fluorescence of QDs was recorded using a Perkin-Elmer LS 55 (PerkinElmer, LAS, Germany GmbH, Rodgau juegesheim).

\section{Cellular uptake}

To study the cellular uptake and displacement of QDs-SST, mammary gland, breast; derived from metastatic site: pleural effusion (human, MCF7) were seeded in a 24-well plate at a density of 100000 cells/well in a complete growth medium, and allowed to grow for 2 days, with medium changed once. Then the medium was removed, cells were washed with DPBS and incubated with QDs, QDs-SST, and QDs-SST $+100 \mu \mathrm{M}$ free SST for 1-hour at $37^{\circ} \mathrm{C}$. After incubation, the QDs-SST were removed, and the cells were washed with DPBS and trypsinized. The cells were centrifuged at $300 \times \mathrm{g}$ at $4^{\circ} \mathrm{C}$, washed twice with cold PBS and used for flow cytometry (FACS) analysis. Cells were analyzed on a FACS Calibur (BD Biosciences, San Jose, CA). QDs were excited at $488 \mathrm{~nm}$ and emission was measured using a $655 \mathrm{~nm}$ bandpass filter. Data was analysed using win MDI 2.9 software. 5000 cells were gated from the population of the whole cells and the fluorescence was plotted in a histogram. Each data point represents the mean of three measurements ( \pm SEM). The QDs concentration was determined by fluorimetric measurement in 96-well plate on a LS-55 fluorescence spectrometer (Perkin Elmer, Waltham, MA, USA) using an excitation and emission wavelength of 488 and $655 \mathrm{~nm}$, respectively [48,49].

Furthermore, to study the cellular uptake of QDs-SST using inductively coupled plasma optical spectroscopy, ICP-OES, MCF7 cells were incubated with unmodified QDs (as control nanoparticles) and QDs-SST for 1 hour in RPMI 1640 medium containing serum. The number of QDs per cell was determined by ICP-OES. The initial concentration of QDs in the culture medium was 20nM for unmodified QDs and QDs-SST.

\section{Results and Discussion}

SST-coated-QDs were successfully synthesized and showed a stable colloidal solution without any visible coalescence. Fluorescence emission was observed when all QDs were excited at $488 \mathrm{~nm}$. Collectively, these results indicate that QDs coated with SST have no significantly different fluorescence properties compared to the unmodified QDs. Even though their QDs were chemically modified with SST, they still possess a significant fluorescence. This indicates that the decoration with SST did not affect the fluorescence of QDs. However, the blue shift observed could be due to the conjugation of QDs with SST. The zeta potential of colloidal QDs-SST is often used as an indicator of dispersion stability. It was found that, QDs alone had zeta potential of $-37.92 \pm 0.16 \mathrm{mV}$. After conjugation with SST, the zeta potential showed reversal to positive values $(+23.3 \pm 0.23 \mathrm{mV})$ (Figure 2). The large value of negative zeta potential is the reason of dispersion stability. Furthermore, the inversion of zeta potential is an indication for the binding of the peptide to QDs. Large zeta potentials predict a more stable dispersion [50].

QDs-SST was produced to offer a stable colloidal solution and exhibited no visible coalescence. Nevertheless, the QDs-PEG-amine was chemically modified with SST, they still have a significant fluorescence. This reveals that the coating of QDs with SST did not affect the fluorescence of QDs-PEG-amine. The surface charge also works a fundamental role in the stability of the QDs, and the grade of zeta potential approves the stability of the colloidal system [51]. The extreme zeta potentials afford a more stable dispersion. Moreover, the DLS showed a reversal of zeta potential to positive charges. The extreme zeta potential suggests the distribution stability and the inversion of the zeta potential [50].

\section{Cellular uptake}

QDs-SST exhibited highly specific binding when incubated with MCF7 cells. FACS showed no significant uptake of unmodified QDs to MCF7 cells, while QDs-SST was bound with the cells with strong fluorescence. This finding supports that the particles were successfully delivered into the target cells. Further experiments showed that the 

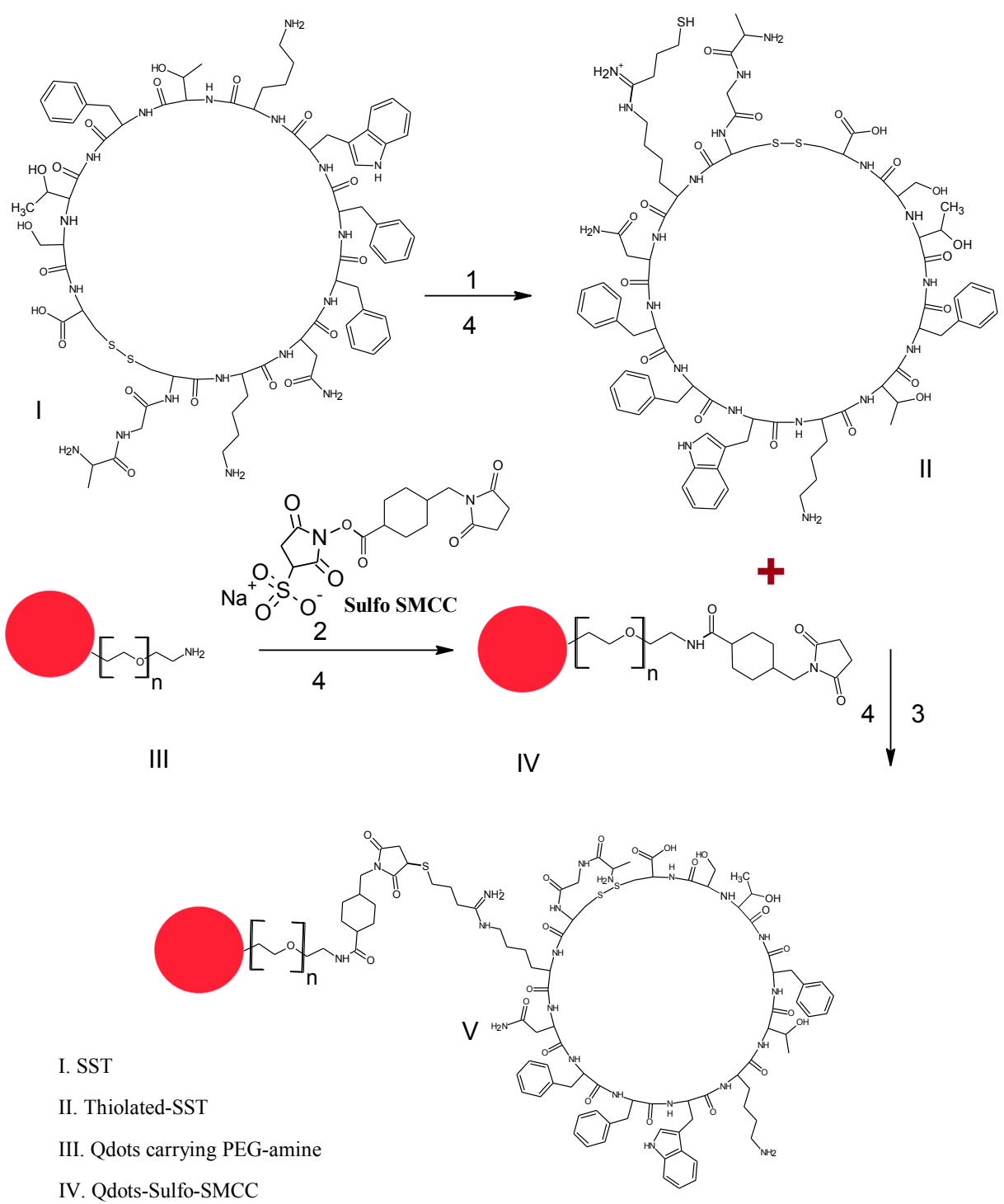

IV. Qdots-Sulfo-SMCC

V. Qdots-SST

Reagents and conditions; 1. Traut's reagent (1.5 eq.) pH 8; 2. Sulfo-SMCC (1000 eq.) pH 8 for 1 hr; 3. Incubation in borate buffer $\mathrm{pH} 8$ for $1 \mathrm{hr} ; 4$. Purification (Sephadex G-25).

Figure 1: Bioconjugation of SST to QDs. The reaction mixture was purified, by running through an equilibrated sephadex G-25 mini-column. Then, QDs activated with sulfo SMCC. The activated QDs-Sulfo-SMCC was conjugated to the thiolated-SST to form SST-QDs. The obtained bio-conjugate was purified using sephadex G-25.

internalization binding was reduced in the presence of free agonist SST $10 \mu \mathrm{M}$. The fluorescence of QDs-SST was significantly decreased when displaced with free SST (Figure 3).

In order to compare the binding of QDs-SST with other formulae. The fluorescence intensities of QDs-SST to MCF7 cells match the results expected for this active targeting. The results showed the high bind of QDs-SST with these cells was due to higher expression of mRNA of SSTR2. The cytotoxicity was tested for these nanoparticles also the IC 50 values were $67 \mathrm{nM}$ for MCF7 cells when they bind to QDs-SST. The results showed no toxicity for QDs on different cell lines reported in this study (Figure 3).
The higher binding of QDs-SST to cells due the expression of higher SSTR2 especially the expression of mRNA of SSTR2 with MCF7 cells as reported previously $[52,53]$. Our data showed that the QDs-SST displayed a high exclusive binding to the SSTR2 which can be displaced from their receptor using high concentrations of SST as agonist occupier. ICP-OES showed also higher binding of QDs-SST to MCF7 cells. Moreover, these results showed that the internalization binding was reduced in the presence of free SST $(10 \mu \mathrm{M})$, due to blocking of receptors. These kinds of receptor-interactions are considered as receptor mediated endocytosis which is crucial for diagnosing, treating, and identifying the cancer cells (Figure 4). 
Citation: Abdellatif AAH (2018) Targeting of Somatostatin Receptors Using Fluorescent Nanoparticles. J Nanomed Nanotechnol 9: 506. doi: 10.4172/2157-7439.1000506

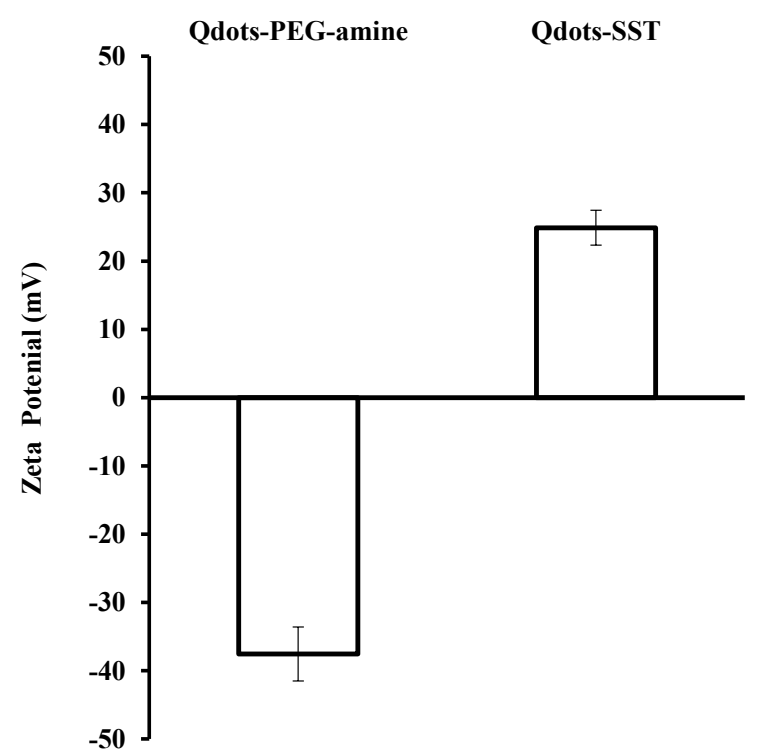

Figure 2: Zeta potential of QDs and QDs coated with SST in DPBS pH 7.4 The zeta potential of QDs-SST showed reversal to positive values. QDs have a negative zeta potential, after conjugation with SST the zeta potential showed reversal to positive values.

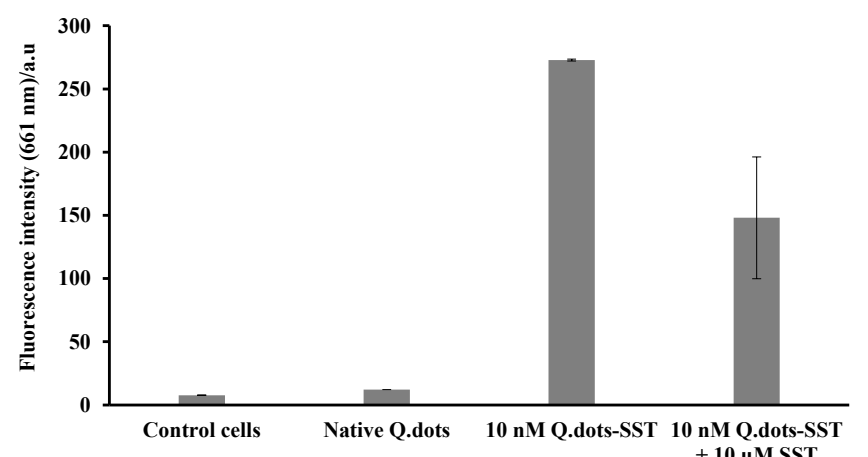

Figure 3: Cell binding of QDs-SST. Cells were incubated with $10 \mathrm{nM}$ of QDsSST. The QDs exhibited binding to the cell surfaces and were displaced with $10 \mu \mathrm{M}$ of free SST.

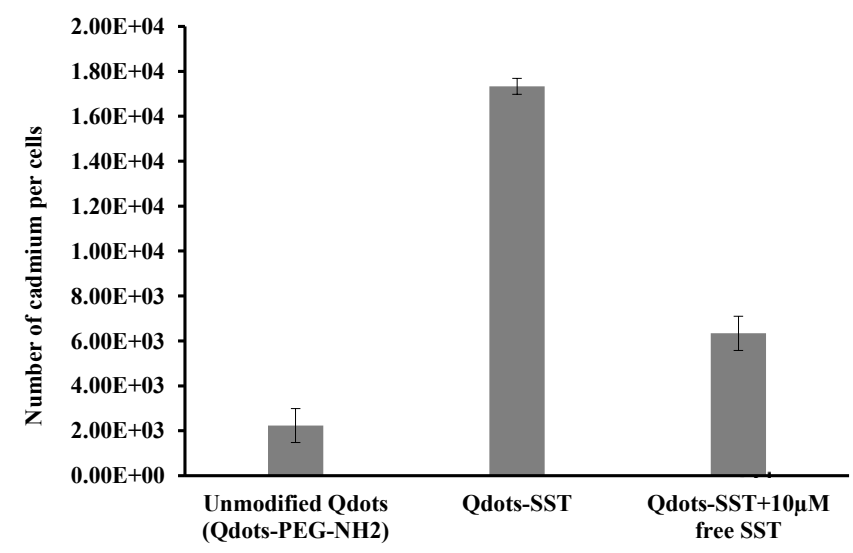

Figure 4: The biodistribution of QDs in MCF7 cells from cells as determined by ICP-OES.

\section{Conclusions}

Thiolation was necessary for the conjugation of SST to QDs. In addition, higher amounts of QDs-SST particles internalized per cell in MCF7 cell lines compared to unmodified QDs and QDs-SST in the presence of high concentration of free SST. Such internalization depends on the surface properties of the cells not on the size of particles as shown when the receptors were blocked by incorporation of the antagonist. Finally, the proof of principle has been addressed and we will be focusing our research in the future in the delivery of these novel QDs coated with SST to various tumour cells.

\section{References}

1. Ren D, Kratz F, Wang SW (2014) Engineered drug-protein nanoparticle complexes for folate receptor targeting. BiochemEng J 89: 33-41.

2. Maina T, Cescato R, Waser B, Tatsi A, Kaloudi A, et al. (2014) [111/nDOTA]LTT-SS28, a first pansomatostatinradioligand for in vivo targeting of somatostatin receptor-positive tumors. J Med Chem 57: 6564-6571.

3. Bertrand N, Leroux JC (2012) The journey of a drug-carrier in the body: An anatomo-physiological perspective. Journal of Controlled Release 161: 152-163.

4. Ehmer $U$ (2003) Identification of two functional polymorphisms of the human hepatic Ugt1a4 gene: Implications for drug therapy and genetic disease predisposition. Gastroenterology 124: A723-A723.

5. Belalcazar LM (2000) Somatic gene therapy for long-term stable correction of genetic $\mathrm{HDL}$ deficiency and atherosclerotic disease in mice using a novel nontoxic adenoviral human ApoA-I vector. Circulation 102: 163-164.

6. Friedmann T, Roblin R (1972) Gene therapy for human genetic disease? Science 175: 949-955

7. Hoyer D, Bell GI, Berelowitz M, Epelbaum J, Feniuk W, et al. (1995) Classification and nomenclature of somatostatin receptors. Trends PharmacolSci 16: 86-88.

8. Patel YC1 (1999) Somatostatin and its receptor family. Front Neuroendocrinol 20: 157-198.

9. Zhou G, Sinnett-Smith J, Liu SH, Yu J, Wu J, et al. (2014) Down-regulation of pancreatic and duodenal homeobox-1 by somatostatin receptor subtype 5: a novel mechanism for inhibition of cellular proliferation and insulin secretion by somatostatin. Front Physiol 5: 226.

10. Woelfl S, Bogner S, Huber H, Salaheddin-Nassr S, Hatzl M, et al. (2014) Expression of somatostatin receptor subtype 2 and subtype 5 in thyroid malignancies. Nuklearmedizin 53: 179-185.

11. Li D, Wu Z, Yu Y, Ball RG, Guo L, et al. (2014) Diamine Derivatives as Nove Small-Molecule, Potent, and Subtype-Selective Somatostatin SST3 Receptor Agonists. ACS Med ChemLett 5: 690-695.

12. Tostivint $H$, OcampoDaza D, Bergqvist CA, Quan FB, Bougerol $M$, et al (2014) Molecular evolution of GPCRs: Somatostatin/urotensin II receptors. J MolEndocrinol 52: T61-86.

13. Karavitakis M, Msaouel P, Michalopoulos V, Koutsilieris M (2014) Pattern of somatostatin receptors expression in normal and bladder cancer tissue samples. Anticancer Res 34: 2937-2942.

14. Imperiale A, Chenard MP, Rohr S, Barlier A, Goichot B (2014) In vivo and in vitro evidence of somatostatin receptors expression in a dedifferentiated retroperitoneal liposarcoma. ClinNucl Med 39: 892-893.

15. Gahete MD, Durán-Prado M, Delgado-Niebla E, Garrido JJ, Rhodes SJ, et al. (2014) Porcine sst1 can physically interact with other somatostatin receptors and its expression is regulated by metabolic/inflammatory sensors. Am J PhysiolEndocrinolMetab 306: E483-493.

16. Petrak K (2005) Essential properties of drug-targeting delivery systems. Drug Discov Today 10: 1667-1673.

17. Lichtenauer-Kaligis EG (2004) Differential expression of somatostatin receptor subtypes in human peripheral blood mononuclear cell subsets. European Journal of Endocrinology 150: 565-77.

18. Reynaert H, van Rossen E, Uyama N, Chatterjee N, Kumar U, et al. (2007) Expression of somatostatin receptors in splanchnic blood vessels of normal and cirrhotic rats. Liver Int 27: 825-831. 
Citation: Abdellatif AAH (2018) Targeting of Somatostatin Receptors Using Fluorescent Nanoparticles. J Nanomed Nanotechnol 9: 506. doi: 10.4172/2157-7439.1000506

Page 5 of 5

19. Perez J, Viollet C, Doublier S, Videau C, Epelbaum J, et al. (2003) Somatostatin binds to murine macrophages through two distinct subsets of receptors. J Neuroimmunol 138: 38-44.

20. Muscarella LA, D'Alessandro V, la Torre A, Copetti M, De Cata A, et al. (2011) Gene expression of somatostatin receptor subtypes SSTR2a, SSTR3 and SSTR5 in peripheral blood of neuroendocrine lung cancer affected patients. Cell Oncol (Dordr) 34: 435-441.

21. Veld F, Herder C, Mussmann R, Martin S, Kempf K (2007) Somatostatin receptor expression in peripheral blood of type 2 diabetes mellitus patients. HormMetab Res 39: 230-232.

22. Bhathena SJ, Recant $L$ (1980) Somatostatin receptors on circulating human blood cells. HormMetab Res 12: 277-278.

23. Rufini V, Calcagni ML, Baum RP (2006) Imaging of neuroendocrine tumors. SeminNucl Med 36: 228-247.

24. Taniyama Y, Suzuki T, Mikami Y, Moriya T, Satomi S, et al. (2005) Systemic distribution of somatostatin receptor subtypes in human: an immunohistochemical study. Endocr J 52: 605-611.

25. Sabaeian M, Khaledi-Nasab A (2012) Size-dependent intersubband optical properties of domeshaped. InAs/GaAs quantum dots with wetting layer. Appl Opt 51: 4176-4185.

26. Gammon D (2000) Electrons in artificial atoms. Nature 405: 899-900.

27. Murray CB, Kagan CR, Bawendi MG (2000) Synthesis and Characterization of Monodisperse Nanocrystals and Close-Packed Nanocrystal Assemblies. Annual Review of Materials Science 30: 545-610.

28. Ramírez HY, Flórez J, Camacho AS (2015) Efficient control of coulomb enhanced second harmonic generation from excitonic transitions in quantum dot ensembles. Physical Chemistry Chemical Physics 17: 23938-23946.

29. Coe-Sullivan S, Steckel JS, Woo WK, Bawendi MG, Bulović V (2005) LargeArea Ordered Quantum-Dot Monolayers via Phase Separation During SpinCasting. Advanced Functional Materials 15: 1117-1124.

30. Walling MA, Novak JA, Shepard JRE (2009) Quantum Dots for Live Cell and In Vivo Imaging. Int J Mol Sci 10: 441-491.

31. Michalet X, Pinaud FF, Bentolila LA, Tsay JM, Doose S, et al. (2005) Quantum Dots for Live Cells, in Vivo Imaging, and Diagnostics. Science 307: 538-544.

32. Lane LA, Smith AM, Lian T, Nie S (2014) Compact and Blinking-Suppressed Quantum Dots for Single-Particle Tracking in Live Cells. J Phys Chem B 118: 14140-14147.

33. (2014) Paul Selvin Hot Topics presentation: New Small Quantum Dots for Neuroscience. SPIE

34. Tokumasu F, Fairhurst RM, Ostera GR, Brittain NJ, Hwang J, et al. (2005) Band 3 modifications in Plasmodium falciparum-infected $A A$ and $C C$ erythrocytes assayed by autocorrelation analysis using quantum dots. J Cell Sci 118: 1091-1098.

35. Dahan M, Levi S, Luccardini C, Rostaing P, Riveau B, et al. (2003) Diffusion Dynamics of Glycine Receptors Revealed by Single-Quantum Dot Tracking. Science 302: 442-445.
36. Akerman ME, Chan WC, Laakkonen P, Bhatia SN, Ruoslahti E et al. (2008) Monovalent, reduced-size quantum dots for imaging receptors on living cells. Nature Methods 5: 397-399.

37. Akerman ME, Chan WC, Laakkonen P, Bhatia SN, Ruoslahti E (2002) Nanocrystal targeting in vivo. Proceedings of the National Academy of Sciences 99: 12617-12621.

38. Farlow J, Seo D, Broaders KE, Taylor MJ, Gartner ZJ, et al. (2013) Formation of targeted monovalent quantum dots by steric exclusion. Nature Methods 10 1203-1205.

39. Dwarakanath S, Bruno JG, Shastry A, Phillips T, John AA, et al. (2004) Quantum dot-antibody and aptamer conjugates shift fluorescence upon binding bacteria. Biochem Biophys Res Commun 325: 739-743.

40. Ballou B, Lagerholm BC, Ernst LA, Bruchez MP, Waggoner AS (2004) Noninvasive Imaging of Quantum Dots in Mice. Bioconjugate Chemistry 15: 79-86.

41. Moaeen-Ud-Din M, Yang LG (2009) Evolutionary history of the somatostatin and somatostatin receptors. J Genet 88: 41-53.

42. Reisine T, Woulfe D, Raynor K, Kong H, Heerding J, et al. (1995) Interaction of somatostatin receptors with $\mathrm{G}$ proteins and cellular effector systems. Ciba Found Symp 190: 160-167.

43. Bell GI, Yasuda K, Kong H, Law SF, Raynor K, et al. (1995) Molecular biology of somatostatin receptors. Ciba Found Symp 190: 65-79.

44. Florio T, Rim C, Hershberger RE, Loda M, Stork PJ (1994) The Somatostatin Receptor Sstr1 Is Coupled to Phosphotyrosine Phosphatase-Activity in Cho-K1 Cells. Mol Endocrinol 8: 1289-1297.

45. Lahlou H, Guillermet J, Hortala M, Vernejoul F, Pyronnet S, et al. (2004) Molecular signaling of somatostatin receptors. Ann N Y Acad Sci 1014: 121-31.

46. Abdellatif AAH (2015) Gold Nanoparticles Decorated With Octreotide For Somatostatin Receptors Targeting. J Pharm Sci \& Res 7: 14-20.

47. Abdellatif AAH, Abdelhafez WA, Sarhan HA (2018) Somatostatin Decorated Quantum Dots Nanoparticles for Targeting of Somatostatin Receptors. Iranian Journal of Pharmaceutical Research 17: 513-524.

48. Cai W, Chen X (2008) Preparation of peptide-conjugated quantum dots for tumor vasculature-targeted imaging. Nat Protoc 3: 89-96

49. Pollinger K, Hennig R, Breunig M, Tessmar J, Ohlmann A, et al. (2012) Kidney podocytes as specific targets for cyclo(RGDfC)-modified nanoparticles. Small 8: 3368-3375

50. Greenwood R, Kendall K (1999) Selection of suitable dispersants for aqueous suspensions of zirconia and titania powders using acoustophoresis. Journal of the European Ceramic Society19: 479-488.

51. Abdellatif AA, Abou-Taleb HA (2016) Transfersomal nanoparticles of keratolytic and antibacterial agents for enhanced transdermal delivery. J Nano Adv Mat 4 19-23.

52. Abdellatif A (2015) Octreotide Labelled Fluorescein Isothiocyanate for Identification of Somatostatin Receptor Subtype 2. Biochem Physiol 4: 2.

53. Abdellatif AA, Zayed G, El-Bakry A, Zaky A, Saleem IY, et al. (2016) Nove gold nanoparticles coated with somatostatin as a potential delivery system for targeting somatostatin receptors. Drug Dev Ind Pharm 42: 1782-1791. 